\title{
Evaluation on efficacy and safety of tyrosine kinase inhibitors plus radiotherapy in NSCLC patients with brain metastases
}

\author{
Shuimei Luo ${ }^{1, *}$, Long Chen ${ }^{2, *}$, Xiuping Chen ${ }^{3}$ and Xianhe Xie ${ }^{1}$ \\ ${ }^{1}$ Department of Chemotherapy, The First Affiliated Hospital of Fujian Medical University, Fuzhou, Fujian, China \\ 2 Intensive Care Unit, The First Affiliated Hospital of Fujian Medical University, Fuzhou, Fujian, China \\ ${ }^{3}$ Department of Oncology, Fuzhou Pulmonray Hospital, Fuzhou, Fujian, China \\ * These authors have contributed equally to this work \\ Correspondence to: Xianhe Xie, email: xiexianhe@yahoo.com
}

Keywords: non-small cell lung cancer, brain metastasis, tyrosine kinase inhibitor, radiotherapy, chemotherapy

Received: March 20, $2015 \quad$ Accepted: May 18, $2015 \quad$ Published: May 25, 2015

This is an open-access article distributed under the terms of the Creative Commons Attribution License, which permits unrestricted use, distribution, and reproduction in any medium, provided the original author and source are credited.

\section{ABSTRACT}

Objective: The study was designed to evaluate the efficacy and safety of tyrosine kinase inhibitors (TKIs) plus radiotherapy in patients with brain metastases (BM) of non-small cell lung cancer.

Methods: Medline PubMed, Google Scholar, Web of Science, Oxford Journals Collection, clinical trials and current controlled trials were searched to identify relevant publications. After screening literature and undertaking quality assessment and data extraction, the meta-analysis was performed using RevMan5.3 software.

Results: Eight controlled trials (980 participants) were included in the study. Compared with radiotherapy without TKIs (non-TKI-group), TKIs plus radiotherapy (TKI-group) had a significant benefit on objective response rate (ORR) ( $R R=1.56$, 95\%CI $[1.25,2.03] ; P=0.0008)$, significantly prolonged the time to central nerves system progression (CNS-TTP) $(\mathrm{HR}=0.58,95 \% \mathrm{CI}[0.35,0.96] ; P=0.03)$ and median overall survival (MOS) (HR $=0.68,95 \%$ CI $[0.47,0.98] ; P=0.04$ ) of NSCLC patients with $B M$. There was no significant difference in overall severe adverse events (Grade $\geq 3)(R R=1.49,95 \% C I[0.88,2.54] ; P=0.14)$ between two groups.

Conclusion: This meta-analysis showed TKI-group produced superior response rate when compared with non-TKI-group. TKIs plus radiotherapy significantly prolong the CNS-TTP and MOS of patients without enhancing overall severe adverse events.

\section{INTRODUCTION}

Worldwide, lung cancer ranks a top occurrence rate among malignant tumor with a rare 5-years survival rate $(<15 \%)[1]$, of which non-small cell lung cancer (NSCLC) accounts for about 80\%. Approximately 20$40 \%[2,3]$ of NSCLCs develop brain mestastases (BM) with poor overall survival (OS) of only 3-6 months and severe neurological symptoms [4-6]. Current treatment options include surgical resection, whole brain radiation therapy (WBRT), stereotactic radiosurgery (SRS) alone or combined strategies. Radiotherapy remains the standard therapy for BM from NSCLC, however, long term results remain disappointing with a median survival time in the range of 2.4-4.8 months [7-9] due to the limitations of radiotherapy. Recent studies of radiotherapy in combination with conventional chemotherapeutics agents, such as platinum, nitrosourea, paclitaxel, temozolomide, suggest no significant improvement in OS compared with radiotherapy alone [10-15] owing to their low capacity of penetrating the brain-blood barrier (BBB). Thus, optimal treatment modalities are urgently needed for NSCLC patients with BM.

The epidermal growth factor receptor (EGFR) which expresses in a variety of human cancer cells, including ovarian, breast, colon, prostate and NSCLC [16, 17], is a transmembrane receptor protein identified primarily on cells of epithelial origin [18]. Autophosphorylation of its intracellar domain initiates a cascade of events leading to cell proliferation. 
Table 1: Characteristics of trials included in the Meta-analysis

\begin{tabular}{|c|c|c|c|c|c|c|c|c|c|c|c|c|}
\hline \multirow[t]{2}{*}{ Study ID } & \multirow[t]{2}{*}{ country } & \multirow{2}{*}{$\begin{array}{l}\text { Trial } \\
\text { phase }\end{array}$} & \multirow[t]{2}{*}{$N(T / C)$} & \multirow{2}{*}{$\begin{array}{l}\text { Male } \\
(\mathrm{T} / \mathrm{C}, \%)\end{array}$} & \multirow{2}{*}{$\begin{array}{l}\text { Ages } \\
\text { (T/C,Years) }\end{array}$} & \multicolumn{2}{|c|}{ Interventions } & \multicolumn{5}{|c|}{ outcomes } \\
\hline & & & & & & TKI-group & Non-TKI-group & ORR & OS & CNS-TTP & PFS & $\begin{array}{l}\text { Adverse event } \\
\text { (grade } \geq 3 \text { ) }\end{array}$ \\
\hline Lee et al. 2014 & Britain & II & $40 / 40$ & $37.5 / 52.5$ & $61.3 / 62.2$ & erlotinib+WBRT & placebo+WBRT & $\mathrm{N}$ & $\mathrm{Y}$ & $\mathrm{Y}$ & $\mathrm{N}$ & $\mathrm{Y}$ \\
\hline Zhuang et al. 2013 & China & II & $23 / 31$ & $43 / 42$ & $60 / 63$ & erlotinib+WBRT & WBRT & Y & $\mathrm{Y}$ & $\mathrm{Y}$ & Y & $\mathrm{Y}$ \\
\hline Sperduto et al. 2013 & America & III & $41 / 44$ & $\mathrm{~N}$ & $61 / 64$ & erlotinib+WBRT/SRS & WBRT/SRS & $\mathrm{N}$ & $\mathrm{Y}$ & $\mathrm{Y}$ & $\mathrm{N}$ & $\mathrm{Y}$ \\
\hline Fu et al. 2012 & China & $\mathrm{N}$ & $38 / 123$ & $\mathrm{~N}$ & $\mathrm{~N}$ & gefitinib+WBRT/SRS & WBRT/SRS & $\mathrm{Y}$ & $\mathrm{N}$ & $\mathrm{N}$ & $\mathrm{N}$ & $\mathrm{Y}$ \\
\hline Pesce et al. 2011 & Switzerland & II & $16 / 43$ & $56 / 63$ & $57 / 63$ & gefitinib+WBRT & TMZ+WBRT & $\mathrm{N}$ & $\mathrm{Y}$ & $\mathrm{N}$ & $\mathrm{N}$ & Y \\
\hline Wang et al. 2014 & China & $\mathrm{N}$ & $37 / 36$ & $67.6 / 63.9$ & $61 / 62$ & gefitinib+3D-CRT & $\mathrm{VMP}+3 \mathrm{D}-\mathrm{CRT}$ & $\mathrm{Y}$ & Y & $\mathrm{N}$ & $\mathrm{N}$ & $\mathrm{Y}$ \\
\hline Cai et al. 2014 & China & $\mathrm{N}$ & $104 / 178$ & $59.6 / 66.3$ & $65 / 65$ & TKI+WBRT/SRS/S & WBRT/SRS/S & $\mathrm{N}$ & $\mathrm{Y}$ & $\mathrm{Y}$ & $\mathrm{N}$ & $\mathrm{N}$ \\
\hline Fan et al. 2013 & China & $\mathrm{N}$ & $75 / 111$ & $57.3 / 73.0$ & $57 / 57$ & TKI+WBRT/SRS/S & $\begin{array}{l}\text { chemotherapy+ } \\
\text { WBRT/SRS/S }\end{array}$ & $\mathrm{N}$ & $\mathrm{Y}$ & $\mathrm{N}$ & $\mathrm{N}$ & $\mathrm{N}$ \\
\hline
\end{tabular}

Abbreviation: N(T/C): number of patients(test group/control group); ORR: object response rate; OS: overall survival; CNS-TTP: time to central nerves system/neurological progression/ neurological progression-free survival/ progression-free survival of intracranial disease/ local progression-free survival; PFS: progression-free survival; N: no mention in the paper; Y: have mentioned in the paper.

Fortunately, EGFR signal pathway can be blocked by small-molecule tyrosine kinase inhibitors (TKIs), including gefitinib and erlotinib, which targeting the EGFR to suppress cancer cell proliferation, invasion and metastases $[19,20]$. Currently, TKIs have become increasingly important medications for advanced NSCLC treatment. Some studies showed favourable efficacy and safety in treating patients with BM [21$25]$ while other studies failed to confirm that [26, 27]. The role of TKIs plus radiotherapy for the treatment of BM patients is contraversial. Therefore, we have conducted a meta-analysis to assess the efficacy and safety of TKIs plus radiotherapy versus regimens with conventional chemotherapeautic agents plus radiotherapy or radiotherapy alone.

\section{RESULTS}

\section{Selection of studies}

Totally, 2460 studies were screened which met our selection criteria after searching the relevant databases; 456 of these studies were excluded due to duplication. By verifying related terms in the titles and abstracts, 1967 irrelevant articles and another 29 unfit designed articles were excluded after the full text was analyzed. Finally, eight clinical control trials [21-28] were identified for the present meta-analysis. A flowchart depicting the study selection is shown in Figure 1.

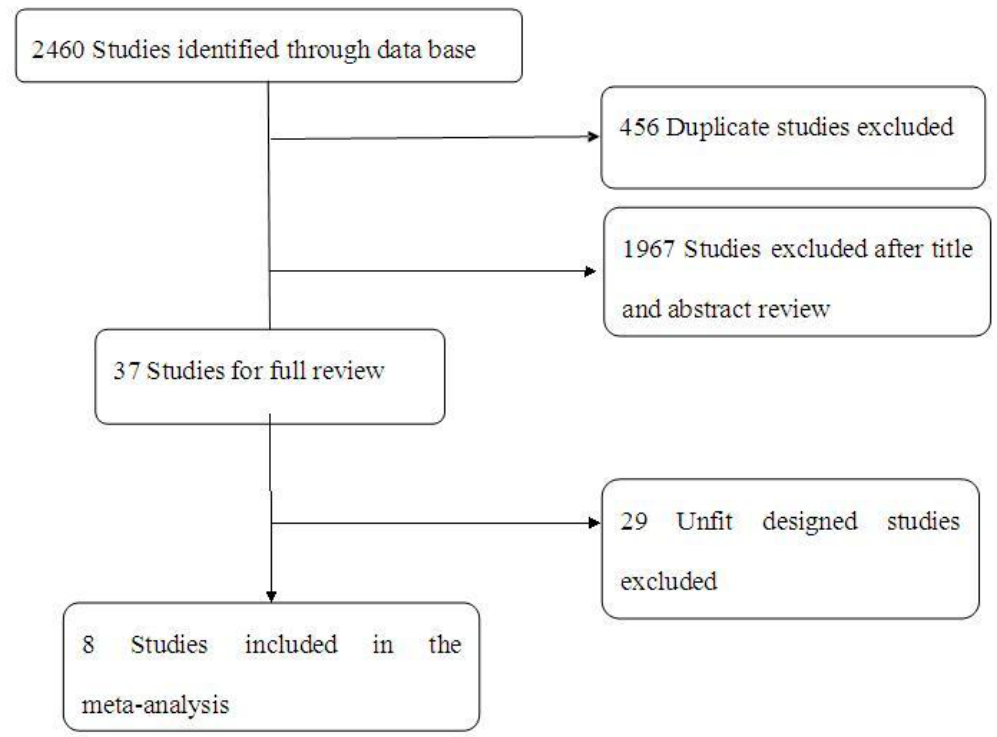

Figure 1: A flow chart on selection included of trials in the Meta-analysis. 


\section{General characteristics of included studies}

There were 980 patients with BM originating from NSCLC in the eight selected controlled trials, consisting of 374 patients with TKIs combined with radiotherapy, 376 patients with only radiotherapy, and 230 patients with conventional chemotherapy plus radiotherapy. These results are summarized in Table 1. Among these eight included studies, one was phase III clinical trials [27], three were phase II studies [21, 26, 28], and four studies didn't mention a trial phase [22-25]. Four of the studies involved in TKIs plus radiotherapy (TKI-group) versus radiotherapy alone (non-TKI-group) [21, 22, 24, 27], the others were TKIs combined with radiotherapy (TKIgroup) versus conventional chemotherapy combined with radiotherapy (non-TKI-group) [23, 25, 26, 28]. Among all of the included studies, conventional chemotherapy drugs included placebo, temozolomide (TMZ), VMP, pemetrexed, gemcitabine, platinum, and other chemotherapy agents. Outcomes included ORR, MOS, CNS-TTP, and overall severe adverse event (grade $\geq 3$ ).

Data for all characteristics are summarized in Table 2. Sex, RPA(Radiation Therapy Oncology Group Recursive Partitioning Analysis), KPS (Karnofsky performance score), ECOG (Eastern Cooperative Oncology Group), No.of BM (number of brain metastases), extra-cranial metastases, histology were available for $6,4,4,2,6,6,6$ of the 8 trials, respectively. Based on the available data, the histology of NSCLC were adenocarcinoma (61\%) .

\section{Methodological quality}

In accordance with the recommendations of the Cochrane Handbook for Systematic Reviews, we evaluated the eligible studies using the four aspects mentioned above. Four studies [23, 26, 27, 28] mentioned the use of random allocation, but only two of them discussed the methods [27, 28]. One study [21] performed or reported their allocation concealment and blinding methods. None of the trial reported follow-up information. All of the articles applied the intent-to-treat analysis. Seven of the eight eligible studies received B quality scores, only one received $\mathrm{C}$ quality scores, as shown in Figure 2.

\section{Local response rate}

Three of the included studies [21-23] reported response rate of treatment using TKIs plus radiotherapy versus conventional chemotherapy plus radiotherapy or radiotherapy alone. Zhuang et al. [21] reported intracranial tumor ORR in the erlotinib plus WBRT and WBRT alone groups were $95.65 \%$ and $54.84 \%$, respectively. Fu et al. [22] reported intracranial tumor ORR in the gefitinib plus WBRT/SRS and WBRT/SRS alone groups were $31.6 \%$ and $15.4 \%$, respectively. Wang et al. [23] reported intracranial tumor ORR were $54 \%$ and $47 \%$ in the gefitinib

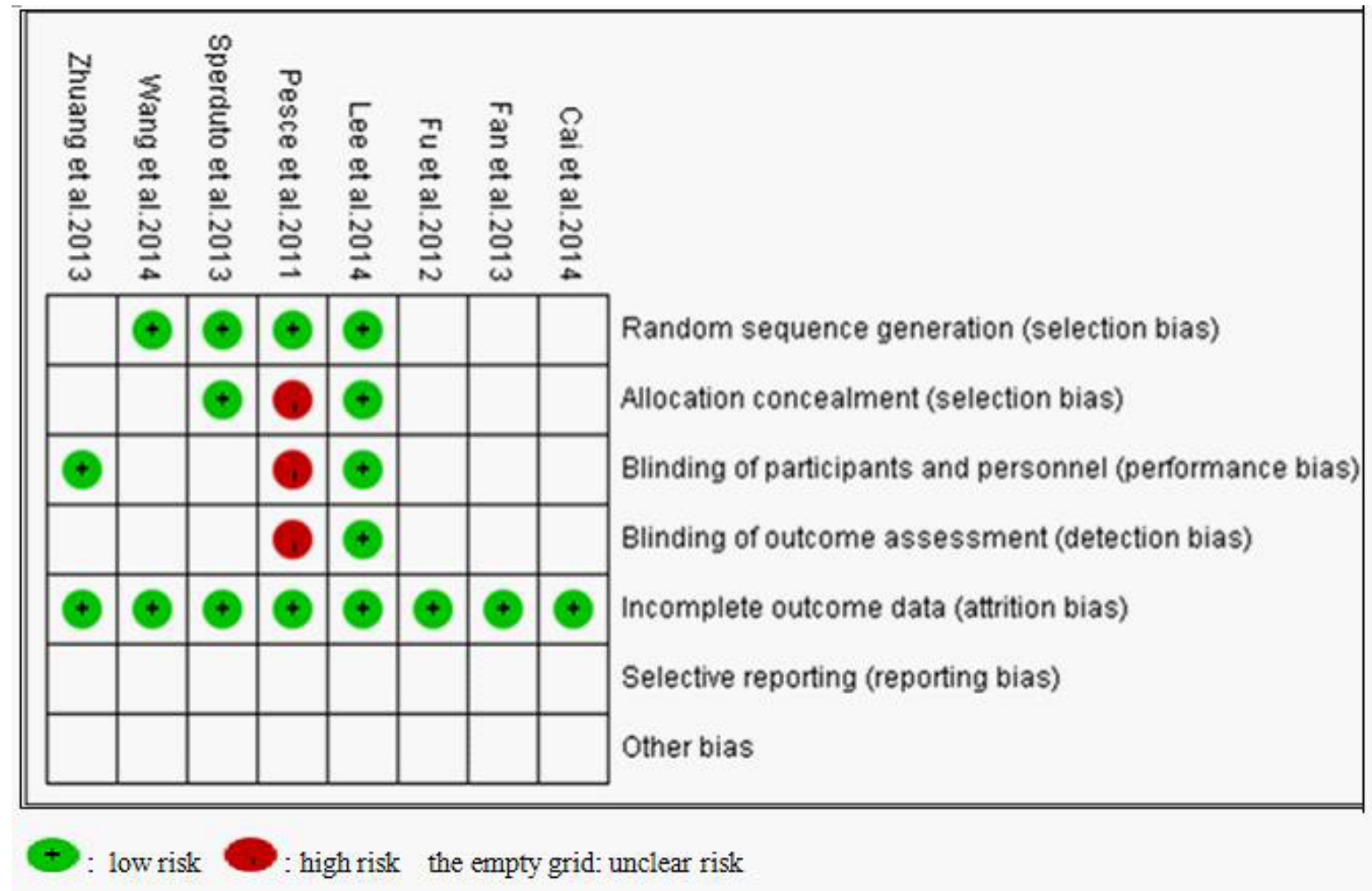

Figure 2: Bias risk and quality assessment of included studies. 
Table 2: Characteristics of included patients

\begin{tabular}{|c|c|c|}
\hline & TKI-group & Non-TKI-group \\
\hline \multicolumn{3}{|l|}{ Sex } \\
\hline Female & $131(35 \%)$ & $156(26 \%)$ \\
\hline Male & $164(44 \%)$ & $283(47 \%)$ \\
\hline unknown & $79(21 \%)$ & $167(27 \%)$ \\
\hline \multicolumn{3}{|l|}{ RPA } \\
\hline Grade 1 & $41(11 \%)$ & $52(8 \%)$ \\
\hline Grade 2 & $119(32 \%)$ & $138(23 \%)$ \\
\hline Grade 3 & $19(5 \%)$ & $36(6 \%)$ \\
\hline unknown & $195(52 \%)$ & $380(63 \%)$ \\
\hline \multicolumn{3}{|l|}{ KPS } \\
\hline$<70$ & $19(5 \%)$ & $36(6 \%)$ \\
\hline$\geqslant 70$ & $160(43 \%)$ & $190(31 \%)$ \\
\hline unknown & $195(52 \%)$ & $380(63 \%)$ \\
\hline \multicolumn{3}{|l|}{ ECOG } \\
\hline $0-1$ & $32(9 \%)$ & $105(17 \%)$ \\
\hline 2 & $13(3 \%)$ & $43(7 \%)$ \\
\hline $3-4$ & $9(2 \%)$ & $18(3 \%)$ \\
\hline unknown & $320(86 \%)$ & $440(73 \%)$ \\
\hline \multicolumn{3}{|l|}{ No.of BM } \\
\hline$\leqslant 3$ & $203(54 \%)$ & $265(44 \%)$ \\
\hline$>3$ & $96(26 \%)$ & $182(30 \%)$ \\
\hline unknown & $75(20 \%)$ & $159(26 \%)$ \\
\hline \multicolumn{3}{|c|}{ Extra-cranial metastases } \\
\hline yes & $173(46 \%)$ & $266(44 \%)$ \\
\hline no & $126(34 \%)$ & $181(30 \%)$ \\
\hline unknown & $75(20 \%)$ & $159(26 \%)$ \\
\hline \multicolumn{3}{|l|}{ Histology } \\
\hline adenocarcinoma & $228(61 \%)$ & $323(53 \%)$ \\
\hline squamous carcinoma & $14(4 \%)$ & $33(5 \%)$ \\
\hline others & $17(4 \%)$ & $31(5 \%)$ \\
\hline unknown & $115(31 \%)$ & $219(36 \%)$ \\
\hline
\end{tabular}

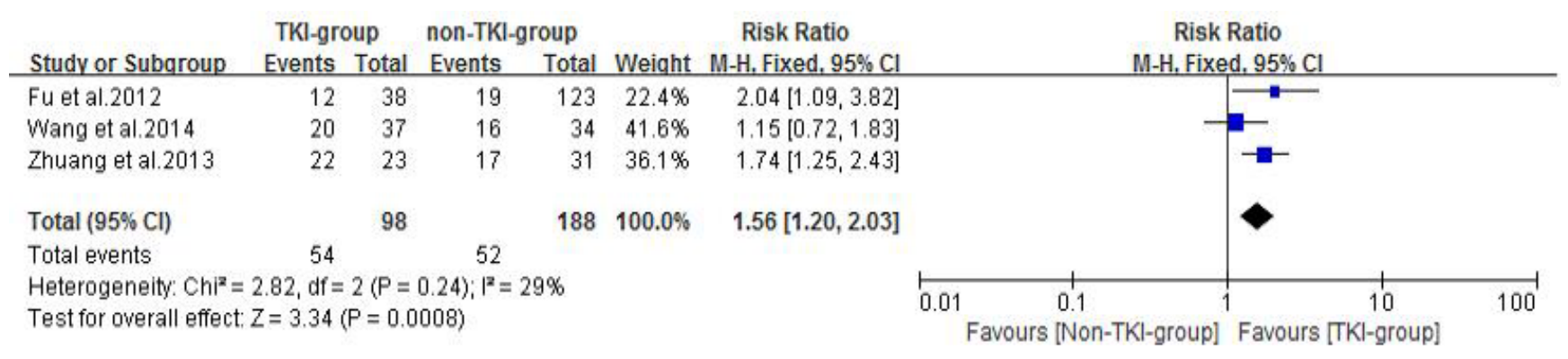

Figure 3: Objective response rate (ORR) of the study. 
combined with 3D-CRT and VMP combined with 3D-CRT arms, respectively. A fixed effects model was used for the meta-analysis of these studies because heterogeneity did not exist $\left(P=0.24, I^{2}=29 \%\right)$. The results indicated that TKI-group produced superior response rates when compared with non-TKI-group $(\mathrm{RR}=1.56,95 \% \mathrm{CI}[1.20$, 2.03]; $P=0.0008$ ) as showed in Figure 3 .

Seven of the studies [21, 23-28] reported median overall survival (MOS) for both patient groups. Analysis using a random effects model based on the heterogeneity values $\left(P=0.0002, I^{2}=77 \%\right)$ of these studies suggested that in NSCLC patients diagnosed with BM, TKIs combined with radiotherapy significantly prolong MOS when compared with conventional chemotherapy combined with radiotherapy or radiotherapy alone $(\mathrm{HR}=0.68,95 \%$ CI $[0.47,0.98] ; P=0.04)$ (Figure 4A). The funnel plot indicated that there was no significant publication bias for included studies on MOS(Figure 4B). Subgroup analysis of TKI plus radiotherapy versus chemotherapy plus radiotherapy also demonstrated a desirable MOS in TKI-group (HR $=0.62,95 \%$ CI $[0.47$, $0.80] ; P=0.0004$ ) (Figure 5). Four studies [21, 24, 26, 27] reported CNS-TTP, and only three [21, 24, 26] with complete data were included in the analyzing using a random effects model based on the heterogeneity values ( $P$ $=0.03, I^{2}=71 \%$ ), suggesting that TKIs plus radiotherapy significantly prolonged CNS-TTP $(\mathrm{HR}=0.58,95 \% \mathrm{CI}$ $[0.35,0.96] ; P=0.03$ ) (Figure 6);

\section{Adverse events}

Six enrolled studies had analyzed the treatmentrelated toxicity and adverse events, one of them (73 patients) [23] was excluded for not reporting the sufficient information of severe adverse events grading. A random effects model was used for the overall severe adverse events analysis of these studies based on the heterogeneity values $\left(P=0.008, I^{2}=71 \%\right)$. The results indicated that the incidence of overall severe adverse events did not differ between the TKI-group and non-TKI-group $(\mathrm{RR}=1.49$, 95\% CI [0.88, 2.54]; $P=0.14$ ) (Figure 7).

The most common adverse events of TKIs are rash, fatigue, nausea/vomiting, diarrhea which are largely mild and fairly tolerable, and pneumonitis rarely occurs. Thus, we performed a subgroup analysis for the severe adverse events as showed in (Figure 8 ). Regarding the fatigue, nausea/vomiting, diarrhea, pneumonitis, and other severe
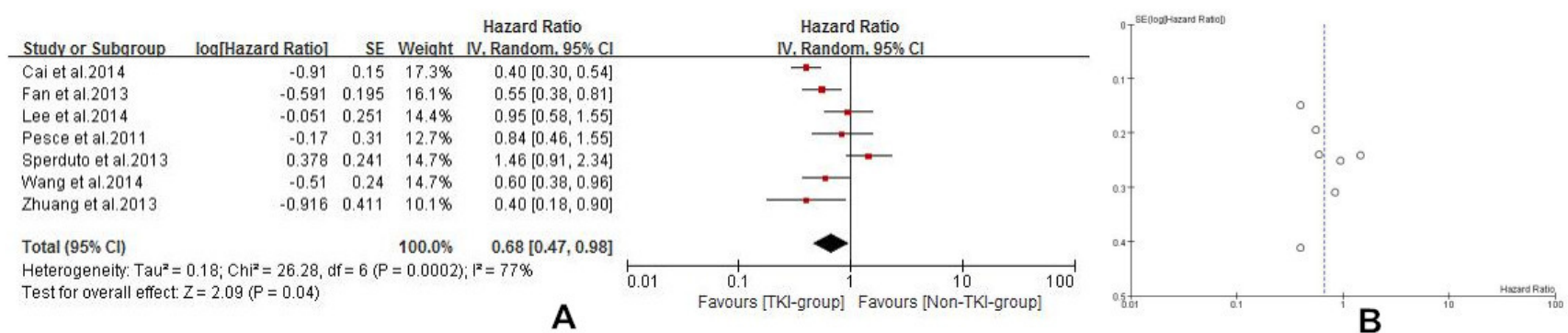

Figure 4: A.Median overall survival (MOS) of the study B. Funnel plot of MOS for included studies.

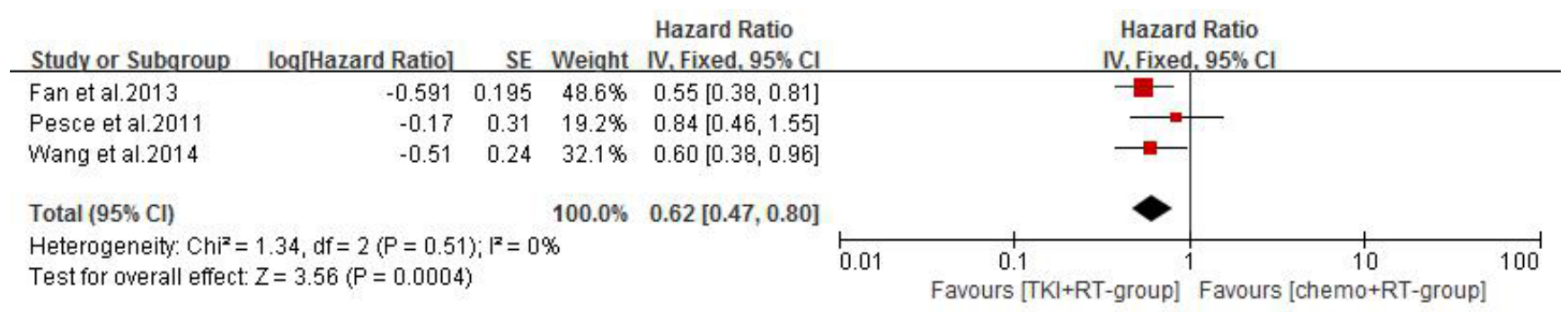

Figure 5: Median overall survival (MOS) of TKI plus radiotherapy versus chemotherapy plus radiotherapy.

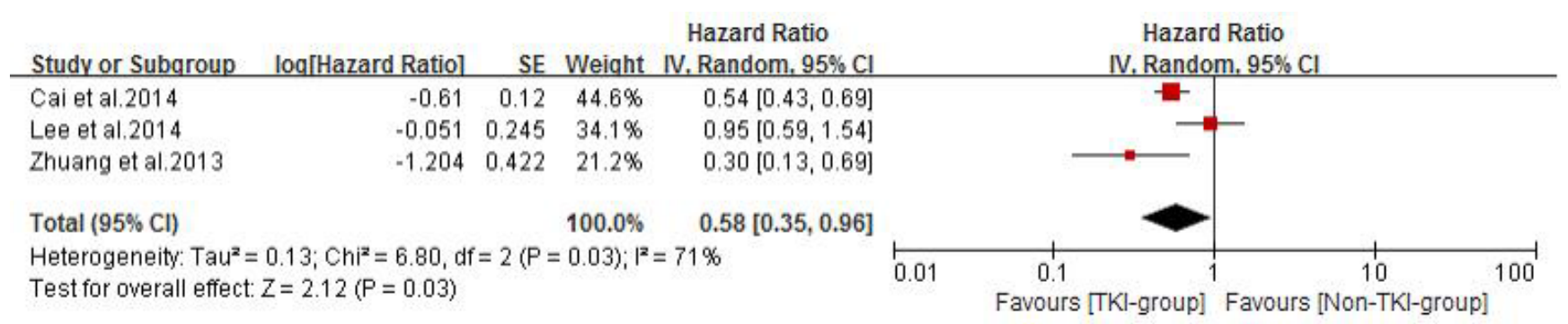

Figure 6: Time to central nerves system progression (CNS-TTP) of the study. 


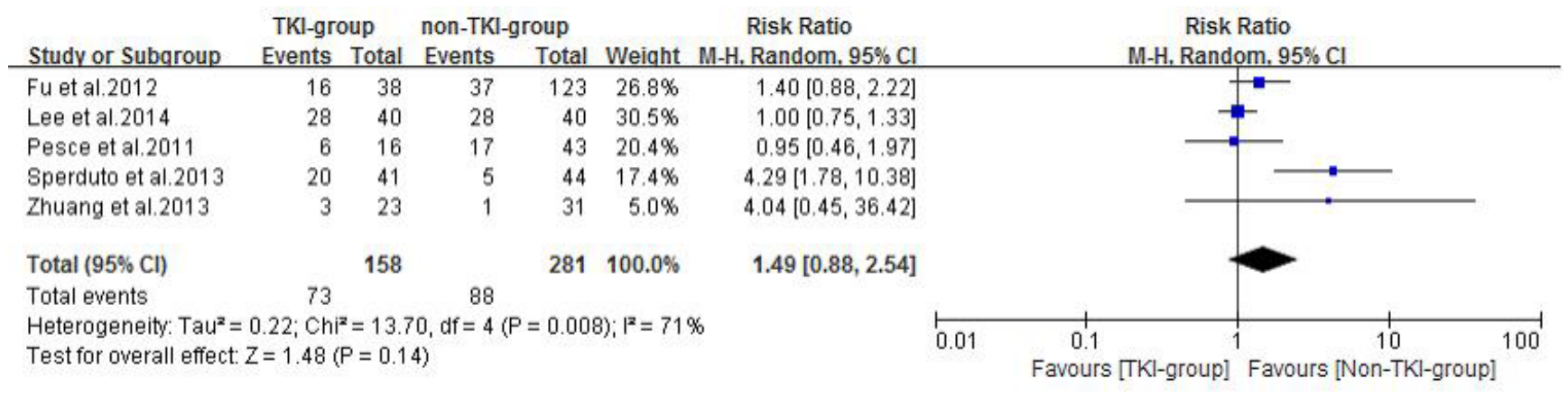

Figure 7: Overall severe adverse events of the study.

\begin{tabular}{|c|c|c|c|c|c|c|c|c|c|c|}
\hline \multirow{2}{*}{$\begin{array}{l}\text { Rash } \\
\text { Stugrer subaroup }\end{array}$} & \multicolumn{2}{|c|}{ Tha-group } & \multicolumn{2}{|c|}{ non-TKa-group } & \multicolumn{2}{|r|}{ Pisk Ratio } & \multicolumn{4}{|c|}{ Risk Ratio } \\
\hline & Events & Total & Events & Tetal & Weiaht & MH.Fixed. $955 \mathrm{Cl}$ & & & $20.955 \mathrm{Cl}$ & \\
\hline Fu et al.2012 & 4 & 38 & 0 & 123 & e.8\% & $28.62 \mathrm{tt} .59,519.80 \mathrm{t}$ & & & 1 & - \\
\hline Lee et al 2014 & B & 40 & 2 & 40 & $73.5 \%$ & 400 10 $90,17,68\}$ & & & & \\
\hline Sperduto et at 2013 & 1 & 41 & 0 & 44 & $17.7 \%$ & $3.21[0.13,76.74]$ & & & & \\
\hline Total $\operatorname{coss} \mathrm{Cn}$ & & 119 & & 207 & 100.05 & $6.02[1.95,18.59]$ & & & & \\
\hline Total events & 13 & & 2 & & & & & & & \\
\hline \multicolumn{7}{|c|}{$\begin{array}{l}\text { Heterogeneity Chi" }=1.55, \mathrm{dr}=2(\mathrm{P}=0.46), \mathrm{P}=0 \% \\
\text { Test for overall effect } z=3.12(P=0.002)\end{array}$} & 0.01 & $\stackrel{0.1}{\text { Favours rthe. }}$ & Favours inon-Tha-groupi & 100 \\
\hline studver subaroup & Events & Tetal & Events & Total & Welaht & M.H. Fixed. 955. CI & \multicolumn{4}{|c|}{$\begin{array}{c}\text { Risk Ratio } \\
\text { M. H. Foxed. } 95 \mathrm{SI}\end{array}$} \\
\hline Fu et al 2012 & 3 & 38 & 7 & 123 & $14.6 \%$ & 1.39 to $38,5.10\}$ & & & & \\
\hline Lee et at 2014 & 7 & 40 & 14 & 40 & $51.9 \%$ & $0.5010 .23,1.111$ & & & & \\
\hline Pesce ot at 2011 & 3 & 16 & e & 43 & $19.2 \%$ & 1.01 io 30,3 33) & & & & \\
\hline Eperdute et at 2013 & 1 & 41 & 1 & 44 & $43 \%$ & $1.0710 .07,16.601$ & & & & \\
\hline Total $(95 \mathrm{~s}$ C) & & 135 & & 250 & $100.0 \mathrm{~s}$ & $0.75[0.43,1.32]$ & & & & \\
\hline \multirow{2}{*}{\multicolumn{5}{|c|}{$\begin{array}{l}\text { Heterogeneity Chi" }=2.16, \text { of }=3 \quad P=0.54), P=03 \\
\text { Test for overall effect } Z=0.99(P=0.32)\end{array}$}} & & & & & & \\
\hline & & & & & & & 0.01 & Favours [Tho-group! & Favours inon-TKl-groupl & 100 \\
\hline studv er subaroup & Events & Total & Events & Tetal & Weight & M.H. Fixed. $95 \mathrm{~s}$ Cl & & A-H. Fixed & $9.95 \% \mathrm{Cl}$ & \\
\hline Fu et at 2012 & 4 & 38 & 11 & 123 & $91.2 \%$ & $1.18[0.40,3.48]$ & & & & \\
\hline Lee et al 2014 & 1 & 40 & 0 & 40 & $0.0 \%$ & $3.00[0.13,71.51]$ & & & & \\
\hline Total $(95 \% \mathrm{cl})$ & & 78 & & 163 & $100.0 \%$ & $1.34[0.48,3.70]$ & & & & \\
\hline Total events & 5 & & 11 & & & & & & & \\
\hline \multicolumn{5}{|c|}{$\begin{array}{l}\text { Heterogeneity Chi* }=0.30 \text {, df }=1 \quad(P=0.58) ; i^{*}=0 \% \\
\text { Test for overall eflect: } Z=0.56(P=0.58)\end{array}$} & & & 0.01 & $\begin{array}{c}\text { ót } \\
\text { Favours trko. }\end{array}$ & $\begin{array}{c}10 \\
\text { Favours }\{\text { tnon-Tha-group }]\end{array}$ & 100 \\
\hline Diarrhea & \multicolumn{2}{|c|}{ The-aroup } & \multicolumn{2}{|c|}{ non-TKL-group } & & Risk Ratio & \multicolumn{4}{|c|}{ Risk Ratio } \\
\hline study or subaroup & Events & Total & Events & Total & Weiaht & M-H. Fixed. $95 \mathrm{~s}, \mathrm{Cl}$ & & 19-H. Fixged & d. $95 \mathrm{~S} \mathrm{Cl}$ & \\
\hline Fu et at 2012 & 3 & 38 & 9 & 123 & $606 \%$ & 1,08 10.31, 3781 & & & & \\
\hline Lee et al 2014 & 2 & 40 & 2 & 40 & $28.5 \%$ & $1.0010 .15,6.761$ & & & & \\
\hline Pesce et at 2011 & 1 & 16 & 0 & 43 & $4.0 \%$ & $7,76$ 10.33, 181,43$\}$ & & & & \\
\hline Bperduto et at 2013 & 1 & 41 & o & 44 & $6.9 \%$ & $3.2110 .13,76.74 j$ & & & & \\
\hline Total (95s CD) & & 135 & & 250 & $100.0 \mathrm{~s}$ & 1.47 [0.60, 3.62$]$ & & & & \\
\hline \multirow{2}{*}{\multicolumn{7}{|c|}{$\begin{array}{l}\text { Heterogeneity Chi" }=1.69 \text {, of }=3(P=0.64), P=0 \% \\
\text { Test for overall effect } Z=0.84(P=0.40)\end{array}$}} & & & & \\
\hline & & & & & & & 0.01 & Favours [rno-group] & Favours inon-TKa-groupl & 100 \\
\hline Lee et al 2014 & 0 & 40 & 1 & 40 & $75.7 \%$ & 0.33 10.01.7.95] & & & & \\
\hline Bperduto et al 2013 & 1 & 41 & o & 44 & $24.3 \%$ & $3.21[0.13,76.74\}$ & & & & \\
\hline $\begin{array}{l}\text { Total }(95 \mathrm{~s} \text { CD } \\
\text { Total events }\end{array}$ & 1 & e1 & 1. & e4 & $100.0 \mathrm{~s}$ & $1.03[0.15,7.10]$ & & & & \\
\hline $\begin{array}{l}\text { Heterogeneity } \mathrm{Chi}^{*}=0 \\
\text { Test for overall effect } z\end{array}$ & $\begin{array}{l}0.98, \text { dr }=1 \\
z=0.03 \text { or }\end{array}$ & $\begin{array}{l}P=1 \\
P=0\end{array}$ & $\begin{array}{l}0.322, r=1 \\
77\end{array}$ & & & & b. 01 & Favours rtho-group! & Favours inon-Tha-groupl & 100 \\
\hline $\begin{array}{l}\text { OHher severe } \\
\text { adverse events } \\
\text { studyer suboroun }\end{array}$ & $\begin{array}{l}\text { TKa-gros } \\
\text { Events } 1\end{array}$ & Total & $\begin{array}{l}\text { non.TKa-g } \\
\text { Eyents }\end{array}$ & roup & & $\begin{array}{l}\text { Risk Ratio } \\
\text { M. Random, est, cI }\end{array}$ & & Risk F & Ratio & \\
\hline study or subaroun & Events & Total & Events & Total & Weiaht & A H. Random. 25s Cl & & M-H Rando & $9 \mathrm{~m}, 95 \mathrm{scl}$ & \\
\hline Fu et al 2012 & 2 & 38 & 10 & 123 & $17.4 \%$ & $0.65[0.15,2.83]$ & & $\bullet$ & & \\
\hline $\begin{array}{l}\text { Lee et a1 } 2014 \\
\text { Pesce et al } 2011\end{array}$ & $\begin{array}{r}10 \\
2\end{array}$ & $\begin{array}{l}40 \\
16\end{array}$ & 9 & 40 & $\begin{array}{l}29.3 \% \\
18.1 \%\end{array}$ & $\begin{array}{l}1.11 \text { i0.51,244] } \\
0.60 ; 014,247]\end{array}$ & & & $=$ & \\
\hline Bperduto of al.2013 & 16 & 41 & 4 & 44 & $249 \%$ & $4.2911 .56,11701$ & & & $\longrightarrow$ & \\
\hline Dhuang et ai 2013 & 3 & 23 & 1 & 31 & $103 \%$ & $404[0.45,36.42\}$ & & & & \\
\hline Total $(95 \mathrm{~s} \mathrm{Cl})$ & & 158 & & 281 & $100.0 \%$ & $1.4 .4[0.64,3.26]$ & & & & \\
\hline Total events & 33 & & 33 & & & & & & & \\
\hline $\begin{array}{l}\text { Heterogeneity: Tau" }=0 \\
\text { Test for overall efrect } Z\end{array}$ & $\begin{array}{l}\text { 0.43, Chi* } \\
=0.09 \%\end{array}$ & $\begin{array}{r}=8.40 \\
=0.36\end{array}$ & ar $=4 \%$ & $0.08) ; 1$ & $1 *=52 \%$ & & & ${ }_{\text {Favours [Tho-oroup] }}^{\text {o.t }}$ & 'Favours thon-Tha-groupl & 100 \\
\hline
\end{tabular}

Figure 8: Subgroup analysis of severe adverse events. 
adverse events, no difference were observed with $(\mathrm{RR}=$ $0.75,95 \%$ CI $[0.43,1.32] ; P=0.32),(\mathrm{R}=1.34,95 \% \mathrm{CI}$ $[0.48,3.70] ; P=0.58),(\mathrm{R}=1.47,95 \% \mathrm{CI}[0.60,3.62]$; $P=0.40),(\mathrm{R}=1.03,95 \% \mathrm{CI}[0.15,7.10] ; P=0.97),(\mathrm{R}$ $=1.44,95 \% \mathrm{CI}[0.64,3.26] ; P=0.38)$. However, rashes were significantly more common in TKI-group (RR = $6.02,95 \%$ CI $[1.95,18.59] ; P=0.002)$.

\section{DISCUSSION}

Currently, local radiotherapy treatment remains the standard regimen of BM patients from NSCLC [32]. Several studies have certified that radiotherapy with chemotherapy benefits NSCLC patients with BM [33-35]. However, because penetration of most chemotherapeutic drugs into the central nervous system (CNS) is isolated primarily by the BBB [36], the treatment was unsatisfied at curing malignant BM lesions. Being small-molecule agents, TKIs possess great advantage to penetrate the BBB. The molecular pathways that mediate brain colonization and the alternative to traditional therapy in clinical investigations in BM from NSCLC have drawn widespread attention [37-41]. One pre-clinical study [42] showed that ${ }^{14} \mathrm{C}$ radiolabeled gefitinib could be detected in the CNS of healthy mice after oral dose of gefitinib reached peak plasma concentrations, which suggested that gefitinib could penetrate the BBB, other studies [4346] also showed that erlotinib appear good permeability through the BBB. Additionally, radiotherapy, immature tumor angiogenesis and edema might amplify the destruction of the BBB and enhanced TKIs uptake and elevated TKIs concentration in cerebrospinal fluid [4753]. After penetrating into the BBB, TKIs exert their anticancer efficacy via following two mechanisms: one is competing with adenosine triphosphate (ATP), the other is to provide sufficient radiosensitizing and therapeutic level in the brain [54-58]. Recently, Togashi et al. [45] reported that CSF concentrations of erlotinib depend on its plasma concentration, and a high-dose administration of erlotinib could lead to its high CSF concentrations, therefore improved its efficacy, especially to refractory CNS metastases of NSCLC patients.

Compared with the conventional chemotherapeutic agents, TKIs appeared favorable effect in treating NSCLC patients with $\mathrm{BM}[23,25,28]$, which mainly resulted from the distinctive property of the drugs, including their small molecular structure and unique anti-tumor mechanism. Meanwhile, the most common adverse events of TKIs contain fatigue, rash, nausea, vomiting, diarrhea which in most cases are mild and tolerable, and interstitial pneumonia rarely appears. Our study demonstrated that there was no significant difference in overall severe adverse events between the TKI and non-TKI groups, except a tendency that non-TKI group had lower incidence of severe adverse events. This may due to the absence of chemotherapy in most of the non-TKI groups [21, 22, 24,
27].

In summary, the present study suggests TKIs combined with radiotherapy produced superior response rates, markedly prolong the CNS-TTP and MOS of NSCLC patients with BM without significantly enhancing overall severe adverse events. Moreover, it is possible to improve the efficacy through increasing the dosage of TKIs. TKIs plus radiotherapy probably open a promising avenue for treating NSCLC patients with brain metastases.

\section{MATERIALS AND METHODS}

\section{Search strategy}

Medline PubMed, Google Scholar, Web of Science, Oxford Journals Collection, randomized controlled trials (RCT) or clininal controlled trails were searched to identify relevant studies in the published literature. The search was performed on December 1, 2014, using both mesh and free text words. The following basic search terms were used: non-small cell lung cancer, brain metastasis, tyrosine kinase inhibitor, gefitinib, erlotinib, afatinib, radiotherapy, chemotherapy, WBRT, SRS, threedimensional conformal radiotherapy (3D-CRT). The search was performed without any language limitations.

\section{Trial identification criteria}

All projects which met the following criteria were eligible: (1) RCT or clinical controlled trails with voluntarily enrolled patients; (2) Patients had histologically or cytologically confirmed NSCLC and had been diagnosed with brain metastases using CT or MRI; (3) The trials were TKIs plus radiotherapy (WBRT/ SRS/ 3D - C RT alone or in combination) which were considered as TKI-group versus conventional chemotherapy plus radiotherapy or radiotherapy alone (both were considered as non-TKI-group). (4) Trials excluded patients with double or multiple primary cancer or presence of unstable systemic disease. (5) The analyses included objective response rate (ORR), OS, time to central nerves system/ neurological progression (CNS-TTP) / neurological progression-free survival (nPFS)/local progressionfree survival (LPFS) / progression-free survival of intracranial disease (PFSI) (all were considered as CNSTTP in this study), severe adverse events (Grade $\geq 3$ ); (6) Response rate was determined using the Response Evaluation Criteria in Solid Tumors (RECIST1.0 or 1.1 version) [21-23]. Complete remission (CR) was defined as disappearance of all target lesions, any pathological lymph nodes (whether target or non-target) must have reduction in short axis to $<10 \mathrm{~mm}$. Partial response (PR) was defined as at least a $30 \%$ decrease in the sum of diameters of target lesions, taking as reference the baseline 
sum diameters. Progressive disease (PD) was defined as at least a $20 \%$ increase in the sum of diameters of target lesions, taking as reference the smallest sum on study (this includes the baseline sum if that is the smallest on study), in addition to the relative increase of $20 \%$, the sum must also demonstrate an absolute increase of at least $5 \mathrm{~mm}$. (Note: the appearance of one or more new lesions is also considered progression). Stable disease (SD) was defined as neither sufficient shrinkage to qualify for PR nor sufficient increase to qualify for PD, taking as reference the smallest sum diameters while on study. (7) Adverse events was evaluated according to the National Cancer Institute Common Terminology Criteria for Adverse Events (version 3.0) [22, 26, 27, 28].

\section{Study selection}

The eligibility assessment was first performed by screening titles and abstracts and subsequently reviewing the full text of articles. The selection of all studies was executed independently, according to the inclusion criteria, by two reviewers [Shuimei Luo and Xiuping Chen]. Disagreement on whether an article should be included was resolved using a third reviewer [Xianhe Xie].

\section{Data extraction}

Two authors [Shuimei Luo and Long Chen] independently extracted data from all the eligible studies. When the extracted data were not uniform, consultation was needed to make a final determination [Xianhe Xie]. All of the studies included in the analysis contain the following data: first author's name, published year, type of study, trial phase, country of origin study, percentage of male, performance status, number of patients, median ages, interventions and outcomes.

\section{Quality assessment}

All of the selected studies were evaluated by two reviewers [Long Chen and Xianhe Xie] according to The Cochrane Handbook for Systematic Reviews of intervention (Version 5.1.0), based on the following criteria: (1) Random sequence generation; (2) Allocation concealment; (3) Blinding of participants and personnel; (4) Blinding of outcome assessment; (5) Incomplete outcome data; (6) Selective reporting; (7) Other bias. Each trial for bias based on the criteria listed above was marked as 'low risk', 'high risk' or 'unclear risk'. Trials were judged as low risk of bias (i.e. A rating) when all criteria were assessed as low risk; Trials were judged as moderate risk of bias (i.e. B rating) or high risk of bias (i.e. C rating) when one or more criteria were assessed as unclear risk or high risk, respectively.

\section{Statistical analysis}

Statistical analyses were performed using RevMan5.3. Chi-square and I-square tests were used to test the heterogeneity of different studies [29]; no heterogeneity was considered to exist when $P>0.1$ and $I^{2}<50 \%$, a fixed-effect model was applied to pool the study results. Significant heterogeneity was found if $P<$ 0.1 and $I^{2}>50 \%$, and a random-effects statistical model was used [30]. ORR, severe adverse events (Grade $\geq 3$ ) were analyzed using dichotomous variables. OS, CNSTTP were calculated using effect variables. Hazard ratios (HRs) with 95\% confidence intervals (CIs) were extracted from papers or from the survival curves when HRs were not available using the methods described by Zhou et al. [31] for CNS-TTP and OS. The event and total number of patients from TKI-group and non-TKI-group in the papers for object response rates (ORR) and severe adverse events, event-based relative risks (RR) with 95\% CI were determined for ORR and severe adverse events extracted from $62.5 \%$ of the trials [21, 22, 26-28]. Publication bias was identified via funnel plot.

\section{CONFLICTS OF INTEREST}

There is no conflict of interest.

\section{REFERENCES}

1. Arrieta O, Saavedra.Perez D, Kuri R, et al. Brain metastasis development and poor survival associated with carcinoembryonic antigen(CEA)level in advanced nonsmall cell lung cancer:a prospective analysis. BMC Cancer. 2009; 9: 119.

2. Soffietti R1, Trevisan E, Rudà R. Targeted therapy in brain metastasis. Curr Opin Oncol. 2012 Nov; 24:679-86.

3. Andrews DW, Scott CB, Sperduto PW, Flanders AE, Gaspar LE, Schell MC, Werner-Wasik M, Demas W, Ryu J, Bahary JP, Souhami L, Rotman M, Mehta MP, Curran WJ Jr. Whole brain radiation therapy with or without stereotactic radiosurgery boost for patients with one to three brain metastases: phase III results of the RTOG 9508 randomised trial. Lancet. 2004; 363:1665-1672.

4. Lippincott and Williams, et al. Principles and practice of radiation oncology. Chang J. Thoracic tumors. 2008; 1078108.

5. Soffietti R, Rudā R, Mutani R. Management of brain metastases. J Neurol. 2002; 249:1357-69.

6. Gaspar L, Scott C, Rotman M. Et al. Recursive partitioning analysis (RPA) of prognostic factors in three Radiation Therapy Oncology Group (RTOG) brain metastases trials. Int J Radiat Oncol Biol Phys. 1997; 37:745-51.

7. Langer CJ, Mehta MP. Current management of brain metastases, with a focus on systemic options. J Clin Oncol. 
2005; 23:6207-6219.

8. Khuntia D, Brown P, Li J, Mehta MP. Whole-brain radiotherapy in the management of brain metastasis. J Clin Oncol. 2006; 24: 1295-1304.

9. Eichler AF, Loeffler JS. Multidisciplinary management of brain metas-tases. Oncologist. 2007; 12:884-898.

10. Antonadou D, Paraskevaidis M, Sarris G, et al. Phase II randomized trial of temozolomide and concurrent radiotherapy in patients with brain metastases. J Clin Oncol. 2002; $20: 3644-3650$.

11. Chua D, Krzakowski M, Chouaid C, et al. Whole-brain radiation therapy plus concomitant temozolomide for the treatment of brain metastases from non-small-cell lung cancer: a randomized, open-label phase II study. Clin Lung Cancer. 2010; 11:176-181.

12. Cortes J, Rodriguez J, Aramendia JM, et al. Front-line paclitaxel/cisplatin-based chemotherapy in brain metastases from non-small-cell lung cancer. Oncology. 2003; 64:2835 .

13. Guerrieri M, Wong K, Ryan G, et al. A randomised phase III study of palliative radiation with concomitant carboplatin for brain metastases from non-small cell carcinoma of the lung. Lung Cancer. 2004; 46: 107-111.

14. Ushio Y, Arita N, Hayakawa T, et al. Chemotherapy of brain metastases from lung carcinoma: a controlled randomized study. Neurosurgery. 1991; 28:201-205.

15. Verger E, Gil M, Yaya R, et al. Temozolomide and concomitant whole brain radiotherapy in patients with brain metastases: a phase II randomized trial. Int J Radiat Oncol Biol Phys. 2005; 61: 185-191.

16. Ciardiello F, Caputo R, Bianco R, et al. Antitumour effect and potentiation of cytotoxic drug activity in human cancer cells by ZD1839 (Iressa), an epidermal growth factor receptor-se lective tyrosine kinase inhibitor. Clin Cancer Res. 2000; 6: 2053-63.

17. Woodburn JR, Barker AJ, Gibson KH, et al. ZD1839, an epidermal growth factor tyrosine kinase inhibitor selected for clinical development. Proc Am Assoc Cancer Res. 1997; 38: 633-4.

18. Wells A. Molecules in focus: EGF receptor. Int J Biochem Cell Biol. 1999; 31: 637-43.

19. Maemondo M, Inoue A, Kobayashi K, et al. Gefitinib or chemotherapy for non-small-cell lung cancer with mutated EGFR. N Engl J Med. 2010; 362: 2380-8.

20. Zou, Y. M., Xiong, H., \& Yu, S. Y. The effect of Gefitinib on the quality of life in patients with advanced non-small cell lung cancer [J]. China Oncology. 2008; 18: 925-928.

21. Zhuang $\mathrm{H}$ et al. Phase II study of whole brain radiotherapy with or without erlotinib in patients with multiple brain metastases from lung adenocarcinoma. Drug Des Devel Ther. 2013; 7:1179-86.

22. Fu H, Zhang XL, Xiao Y, Liu XJ, Long C, Hu YD. Evaluafion of gefitinib plus radiotherapy in non-small-cell lung cancer pafients with brain metastases. Zhonghua Yi
Xue Za Zhi. 2012; 92:524-7.

23. Wang F, Ning F, Liu C, Hao Y, Li L, Yu Z, Chen S, Li B. Comparison of Gefitinib Versus VMP in the Combination with Radiotherapy for Multiple Brain Metastases from Non-small Cell Lung Cancer. Cell Biochem Biophys. 2015; 71:1261-5.

24. Cai L. et al. A comparative analysis of EGFR mutation status in association with the efficacy of TKI in combination with WBRT/SRS/surgery plus chemotherapy in brain metastasis from non-small cell lung cancer. J Neurooncol. 2014; 120:423-30.

25. Fan $Y$ et al. Chemotherapy and EGFR tyrosine kinase inhibitors for treatment of brain metastases from non-smallcell lung cancer: survival analysis in 210 patients. Onco Targets Ther. 2013; 6:1789-803.

26. Lee SM, et al. Randomized Trial of Erlotinib Plus WholeBrain Radiotherapy for NSCLC Patients With Multiple Brain Metastases. J Natl Cancer Inst. 2014; 106.

27. Sperduto PW, Wang M, Robins HI. et al. A Phase 3 Trial of Whole Brain Radiation Therapy and Stereotactic Radiosurgery Alone Versus WBRT and SRS With Temozolomide or Erlotinib for Non-Small Cell Lung Cancer and 1 to 3 Brain Metastases: Radiation Therapy Oncology Group 0320. Int J Radiat Oncol Biol Phys. 2013; 85:1312-8.

28. Pesce GA, Klingbiel D, Ribi K. et al. Outcome, quality of life and cognitive function of patients with brain metastases from non-small cell lung cancer treated with whole brain radiotherapy combined with gefitinib or temozolomide. A randomised phase II trial of the Swiss Group for Clinical Cancer Research (SAKK 70/03). Eur J Cancer. 2012; 48: 377-84.

29. Higgins JP, Thompson SG, Deeks JJ, Altman DG. Measuring inconsistency in meta-analyses. BMJ. 2003; 327:557-60.

30. Ford AC, Forman D, Hunt RH, Yuan Y and Moayyedi P. Helicobacter pylori eradication therapy to prevent gastric cancer in healthy asymptomatic infected individuals: systematic review and meta-analysis of randomised controlled trials. BMJ. 2014; 348:g3174.

31. ZHOU Zhi-rui, ZHANG Tian-song, LI Bo, MAO Zhi, ZENG Xian-tao, LIU Shi. Extracting and transforming of appropriate data of Meta-analysis in survival curve. Chin J Evid Based Cardiovasc. 2014; Vol.6, No.3.

32. Crinò L, Scagliotti GV, Ricci S, et al. Gemcitabine and cisplatin versus mitomycin, ifosfamide, and cisplatin in advanced non-small-cell lung cancer: a randomized phase III study of the Italian Lung Cancer Project. J Clin Oncol. 1999; 17:3522-30.

33. Ushio Y, Arita N, Hayakawa T, Mogami H, Hasegawa H, et al. Chemotherapy of brain metastases from lung carcinoma: a controlled randomized study. Neurosurgery. 1991; 28: 201- 205.

34. Hassler MR, Pfeifer W, Knocke-Abulesz TH, Geissler 
$\mathrm{K}$, Altorjai G, et al. Temozolomide added to whole brain radiotherapy in patients with multiple brain metastases of non-small-cell lung cancer: a multicentric Austrian phase II study. Wien Klin Wochenschr. 2013; 125:481-6.

35. Guerrieri M, Wong K, Ryan G, Millward M, Quong G, Ball DL. A randomised phase III study of palliative radiation with concomitant carboplatin for brain metastases from non-small cell carcinoma of the lung. Lung Cancer. 2004; 46:107-11.

36. Van Vulpen M, Kal HB, Taphoorn MJB, El Sharouni S. Changes in blood-brain barrier permeability induced by radiotherapy: implications for timing of chemotherapy? (Review). Oncol Rep. 2002; 9:683-8.

37. Soffietti R, Trevisan E, Rudà R. Targeted therapy in brain metastasis. Curr Opin Oncol. 2012; 24:679-86.

38. Eichler AF, Chung E, Kodack DP, Loeffler JS, Fukumura D, Jain RK. The biology of brain metastases-translation to new therapies. Nat Rev Clin Oncol. 2011 Jun;8:344-56.

39. Fidler IJ. The role of the organ microenvironment in brain metastasis. Semin Cancer Biol. 2011;21:107-12.

40. Preusser M, Capper D, Ilhan-Mutlu A, Berghoff AS, Birner P, Bartsch R, Marosi C, Zielinski C, Mehta MP, Winkler F, Wick W, von Deimling A. Brain metastases: pathobiology and emerging targeted therapies. Acta Neuropathol. 2012; 123:205-22.

41. Gow CH, Chien CR, Chang YL, Chiu YH, Kuo SH, Shih JY, Chang YC, Yu CJ, Yang CH, Yang PC. Radiotherapy in lung adenocarcinoma with brain metastases: effects of activating epidermal growth factor receptor mutations on clinical response. Clin Cancer Res. 2008; 14:162-8.

42. McKillop D, Hutchison M, Partridge EA, Bushby N, Cooper CM, Clarkson-Jones JA, Herron W, Swaisland HC. Metabolic disposition of Gefitinib, an epidermal growth factor receptor tyrosine kinase inhibitor in rat, dog and man. Xenobiotica. 2004; 34:917-34.

43. Togashi Y, Masago K, Fukudo M, et al. Cerebrospinal fluid concentration of erlotinib and its active metabolite OSI-420 in patients with central nervous system metastases of nonsmall cell lung cancer. J Thorac Oncol. 2010; 5:950-955.

44. Broniscer A, Panetta JC, O’Shaughnessy M, et al. Plasma and cerebrospinal fluid pharmacokinetics of erlotinib and its active metabolite OSI-420. Clin Cancer Res. 2007; 13:1511-1515.

45. Togashi Y, Masago K, Fukudo M, et al. Efficacy of increased-dose erlotinib for central nervous system metastases in non-small cell lung cancer patients with epidermal growth factor receptor mutation.Cancer Chemother Pharmacol. 2011; 68:1089-1092.

46. Masuda T1, Hattori N, Hamada A, et al. Erlotinib efficacy and cerebrospinal fluid concentration in patients with lung adenocarcinoma developing leptomeningeal metastases during gefitinib therapy. Cancer Chemother Pharmacol. 2011; 67:1465-1469.

47. O'Connor MM, Mayberg MR. Effects of radiation on cerebral vasculature: a review. Neurosurgery. 2000; 46:138149.

48. Hutchinson F. Molecular biology of mutagenesis of mammalian cells by ionizing radiation. Semin Cancer Biol. 1993; 4:85-92.

49. Harms-Ringdahl M, Nicotera P, Radford IR. Radiation induced apoptosis. Mutat Res. 1996; 366:171-179.

50. Fukuhara T, Saijo Y, Sakakibara T, et al. Successful treatment of carcinomatous mengingitis with Gefitinib in a patient with lung adenocarcinoma harboring a mutated EGF receptor gene. Tohoku J Exp Med. 2008; 214:359-63.

51. Chua D, Krzakowski M, Chouaid C, Pallotta MG, Martinez JI, et al. Whole-brain radiation therapy plus concomitant temozolomide for the treatment of brain metastases from non-small-cell lung cancer: a randomized, open-label phase II study. Clin Lung Cancer. 2010; 11: 176-181.

52. Verger E, Gil M, Yaya R, Vinolas N, Villa S, et al. Temozolomide and concomitant whole brain radiotherapy in patients with brain metastases: a phase II randomized trial. Int J Radiat Oncol Biol Phys. 2005; 61: 185-191.

53. Neuhaus T, Ko Y, Muller RP, Grabenbauer GG, Hedde JP, et al. A phase III trial of topotecan and whole brain radiation therapy for patients with CNS-metastases due to lung cancer. Br J Cancer. 2009; 100: 291-297.

54. Chinnaiyan P, Huang S, Vallabhaneni G, et al. Mechanisms of enhanced radiation response following epidermal growth factor receptor signaling inhibition by erlotinib (Tarceva). Cancer Res. 2005; 65:3328-35.

55. Lai CS, Boshoff C, Falzon M, Lee SM. Complete response to erlotinib treatment in brain metastases from recurrent NSCLC. Thorax. 2006; 61:91.

56. Weber B, Winterdahl M, Memon A, et al. Erlotinib accumulation in brain metastases from non-small cell lung cancer: visualization by positron emission tomography in a patient harboring a mutation in the epidermal growth factor receptor. J Thoracic Oncol. 2011; 6:1287-1289.

57. Hata A, Kaji R, Fujita S, Katakami N. High-dose erlotinib for refractory brain metastases in a patient with relapsed non-small cell lung cancer. J Thoracic Oncol. 2011; 6:653654.

58. Porta R, Sánchez-Torres JM, Paz-Ares L, et al. Brain metastases from lung cancer responding to erlotinib: the importance of EGFR mutation. Eur Respir J. 2011; 37:624631. 